Educational Research for Social Change (ERSC)

Volume: 7 No. 1, April 2018

pp. 77-93

ersc.nmmu.ac.za

ISSN: 2221-4070

\title{
Multilingualism and (Bi)Literacy Development for Epistemological Access: Exploring Students Experience in the Use of Multilingual Glossaries at a South African University
}

\author{
Vuyokazi Nomlomo \\ University of the Western Cape \\ vnomlomo@uwc.ac.za \\ Misiwe Katiya \\ Fundani Centre/Cape Peninsula University of Technology \\ katiyam@cput.ac.za
}

\begin{abstract}
This paper reports on the findings of a research project that investigated first-year students' experiences in using multilingual glossaries. They were enrolled in an electrical engineering course at a higher education institution in the Western Cape, South Africa. Data were collected by means of questionnaires and focus group interviews with isiXhosaspeaking students to gain an insight into how the glossaries facilitated or constrained their epistemological access to concepts in the field of engineering. Drawing on the concepts of epistemological access, multilingualism, and biliteracy to establish a framework, we argue that the use of multilingual resources (e.g., glossaries) does not necessarily guarantee students' epistemological access to knowledge if their biliteracy skills (reading and writing) are underdeveloped in one of the targeted resource languages. This paper concludes that multilingualism is a necessary transformative approach, but that students' (bi)literacy development in African languages as targeted languages for transformation should also be prioritised and strengthened to facilitate better learning all round.
\end{abstract}

Keywords: biliteracy, epistemological access, multilingualism, glossaries, transformation

Copyright: (C) 2018 Vuyokazi Nomlomo and Fundani

This is an open access article distributed under the terms of the Creative Commons Attribution Non-Commercial License, which permits unrestricted non-commercial use, distribution, and reproduction in any medium, provided the original author and source are credited.

Please reference as: Nomlomo, V. \& Katiya, M. (2018). Multilingualism and (Bi)Literacy Development for Epistemological Access: Exploring Students Experience in the Use of Multilingual Glossaries at a South African University. Educational Research for Social Change, 7(1), 77-93. http://dx.doi.org/10.17159/2221-4070/2018/v7i1a6

\section{Introduction and Background}

Although the African continent has rich cultural and linguistic diversity with more than 2,000 languages (UNESCO, 2010), the question of the language of learning and teaching (LOLT), both in primary and 
tertiary education, continues to be a contentious issue. Almost $50 \%$ of Africa's population are mothertongue speakers of African languages but only $25 \%$ of the African languages are used in secondary education, and only $5 \%$ are used in higher education (UNESCO, 2010). After decades of colonial independence, the colonial languages (Arabic, English, French, Portuguese, and Spanish) continue to dominate in various formal domains such as business and education (Alidou, 2004; Alidou \& Mazrui, 1999; Bamgbose, 2005; Chumbow, 1990; Prah, 2006). On this continent, the negative effects of the use of colonial languages are widely documented, especially in relation to English and French as the main languages of learning and teaching in basic and higher education (Chumbow, 1990; Desai, 2016; Molosiwa, 2005; Nomlomo \& Vuzo, 2014; Prah, 2006).

Similar language trends and challenges are manifest in South Africa. While it is a multilingual country with 11 official languages, South Africa's language practices in basic and higher education still reflect the colonial and apartheid legacy after two decades of democracy (Desai, 2016). The democratic Constitution of the Republic of South Africa (1996) and the Language in Education Policy (Department of Education, 1997) promoted language equality and equity in education. Similarly, the Language Policy for Higher Education (Department of Education, 2002) requires higher education institutions to devise appropriate strategies for promoting multilingualism and the development of all the official languages as academic languages. However, there is a disjuncture between policy and practice as English and Afrikaans remain the main languages of knowledge production and circulation in education although more than $76 \%$ of the South African population are speakers of African languages (Alexander, 2005; Desai, 2016; Heugh, 2003; Prah, 2006). The nine African languages that were accorded official status after 1994 are still marginalised in education (Alexander, 2005; Desai, 2003; Heugh, 2003; Kaschula \& Maseko, 2014; Nomlomo, 2007; Prah, 2006). Due to English hegemony, South Africa is currently producing young people who can hardly read and write in their home languages, and this exacerbates the stigmatisation of African languages in education (Prah, 2006).

Apart from the language policy and practice issues in education, equal physical access and epistemological access to learning in South Africa have also been part of the transformation discourse in education since 1994. With the demise of apartheid education in 1994, students' physical access to higher education in South Africa has increased (Morrow, 1994). This has led to an increase in cultural and linguistic diversity in many higher education institutions. Yet, despite the shift in student demographics with regard to racial and linguistic groups, the language policy practices and curricula in many institutions still reflect the colonial and apartheid worldviews that promote white supremacy and dominance (Heleta, 2016). The teaching and learning materials are still largely prepared for (English) monolingual students (Hibbert, 2011) and there is no provision for African languages. Consequent low academic literacy skills mean many university students struggle with writing academic texts and understanding academic concepts and terminology in their fields of study (Banda, 2006; Fisher \& Scott, 2011). Some students who are confronted with these linguistic and academic challenges face the risk of academic exclusion while others drop out of the system (Fisher \& Scott, 2011).

Hence, recent research findings on students' success in South African higher education indicate that poor achievement and high dropout rates are higher among black students whose home languages are not used in teaching and learning (Moeketsi \& Maile, 2008; Strydom \& Mentz, 2010). This suggests that the language used in teaching and learning is a key factor in facilitating or constraining learners' access to, and success in, learning (UNESCO, 2010). Students' access to learning clearly remains a great epistemological concern in many South African higher education institutions (Madiba, 2010; van der Walt, 2013). 
In order to facilitate access to meaningful learning, certain higher education institutions have taken initiatives to support students' epistemological access through their home languages rather than in English. These universities have made use of various strategies such as code switching, translation of materials, and translanguaging. Additional support materials include multilingual glossaries for various disciplines such as psychology, economics, and science (Antia \& Dyers, 2016; Kaschula \& Maseko, 2014; Mkhize, Dumisa, \& Chitindingu, 2014; Ngcobo, Ndaba, Nyangiwe, Mpungose, \& Jamal, 2016; Paxton \& Tyam, 2010; Plüddemann, Nomlomo, \& Jabe, 2010). These strategies take a transformative and inclusive approach to promoting the use of African languages, and serve to support students' learning in their home languages, which are otherwise stigmatised in education.

While there is growing awareness of innovative multilingual approaches to facilitate students' epistemological access in certain South African higher education institutions, there is less conversation about students' biliteracy developmental levels. More discussion is thus required about how the development of biliteracy might influence students' meaningful access to targeted knowledge, especially when biliteracy is mediated through additional learning support resources such as glossaries that include African languages. Currently there is great concern about black South African youth, especially those from the middle class who experience home language loss in favour of English. As a result, some can hardly read or write in their home languages, and have effectively become monolingual in English (Prah, 2006). These tendencies exacerbate the marginalisation of African languages as academic languages.

In this article, we focus on an educational transformative practice regarding the use multilingual glossaries in a first-year electrical engineering course in one higher education institution of the Western Cape. The study aimed to uncover how students with varying (bi)literacy levels between their home language (isiXhosa) and an additional language (English) experienced the use of multilingual glossaries designed for an electrical engineering course. We argue that the use of multilingual resources, such as glossaries, does not necessarily guarantee students' epistemological access if, in the targeted resource languages, their biliteracy skills (reading and writing) are underdeveloped. We were guided by two questions:

- What are the students' experiences regarding the use of multilingual glossaries for epistemological access to electrical engineering content knowledge?

- In higher education, what are the implications for multilingual and biliteracy development and transformation of students' experience?

Guided by the principles of democracy and social justice (Nagda, Gurin, \& Lopez, 2003), we draw on a conceptual framework that is informed by three interrelated knowledge streams: epistemological access, multilingualism, and biliteracy (Hopewell \& Escamilla, 2014; Hornberger, 2004; Morrow, 1994; Reyes, 2006). An in-depth discussion of these concepts follows.

\section{Multilingualism and Biliteracy for Epistemological Access}

The discourse on access to education has been at the centre of debate since the end of colonialism in Africa (Jansen, 2008). However, it gained momentum with the advent of the Education for All (EFA) movement in the early 1990s (Alexander, 2005; Jansen, 2008).

At the end of apartheid in South Africa, equal access to education was prioritised on the agenda for transformation. At this time, Wally Morrow (1994) drew a distinction between physical access (students' admission or enrolment) and meaningful learning. In his article, Entitlement and 
Achievement in Education, he coined the concept epistemological access (Morrow, 1994) to refer to the meaningful learning required for competency levels to be achieved (Jansen, 2008; Motala, Dieltiens, \& Sayad, 2009). Thus epistemological access continues to be a central principle underlying teaching and learning in South Africa.

Another concept that has received attention in South Africa since the birth of democracy in 1994 is multilingualism. Multilingualism refers to different languages spoken in a particular community, as well as language competencies in a variety of languages (Burcu, Fannin, Montanera, Cummins, 2014; Desai, 2003; Prah, 2006). Currently, there is an abundance of international and local literature on multilingualism as a marker of democracy, equity, inclusion, and social justice in linguistically diverse societies (Burcu et al., 2014; UNESCO, 2010). Also, the educational benefits of multilingualism are widely recognised and documented as noted above (Alexander, 2005; Alidou, 2004; Alidou \& Mazrui, 1999; Bamgbose, 2005; Brock-Utne, 2005; Chumbow, 2013; Desai, 2003; Heugh, 2003; Prah, 2006; UNESCO, 2010; Webb, 2004).

Similarly, bilingualism and biliteracy have received attention in the United States since the 1990s. These terms have been used as a framework in which to assess and understand how bilingual learners acquire English and English language literacy, notably in reading (Hopewell \& Escamilla, 2014; Hornberger, 2004; Reyes, 2006). Thus, there is a strong interrelationship between bilingualism and biliteracy as bilingual learners are able to develop literacy skills in both languages (Giambo \& Szecsi, 2015).

But bilingual competence is not synonymous with biliteracy (Giambo \& Szecsi, 2015). Biliteracy refers to any type of communication that occurs in two or more languages in or around writing for meaning making (Hornberger, 2004). It can be achieved simultaneously or successively. This implies that the degrees of fluency and expertise in the two languages may vary according to contexts and domains (Hopewell \& Escamilla, 2014; Hornberger, 2004; Reyes, 2006). However, while bilingualism affirms the students' home languages, it does not guarantee that they will develop reading and writing literacy in both languages (Reyes, 2006).

Biliteracy, by contrast, refers to the ability to use literacy skills (oral, listening, reading, writing) in both languages, at varying degrees. Biliterate people are able to use the knowledge of the two languages for specific functions and to facilitate language and concept development in the new language (Hornberger, 2004; Reyes, 2006).

Research shows that reading and using materials in the language that is stronger for the student increases the students' literacy performance (Giambo \& Szecsi, 2015). One of the strategies for promoting biliteracy is to allow students to read in both languages, which implies that access be made available to materials in both languages (Giambo \& Szecsi, 2015). In other words, the literacy skills possessed in one language will advance the literacy skills in the other language. Such skills include reading strategies, decoding, phonological awareness, writing, and so forth. This is especially likely if the two languages have similar writing systems (Giambo \& Szecsi, 2015). In this way, bilingual children become biliterate rather than literate in the dominant language only, and they develop abilities to rely on the two languages as linguistic and cognitive resources (Reyes, 2006).

Bilingual and biliteracy practices challenge the deficit or monolingual perspective that condemns the students' (excluded) home languages as inhibitors of cognitive and linguistic growth in the classroom. Hence, biliteracy theories are often used as lenses through which to understand research in teaching and language planning within linguistically diverse contexts (Chumbow, 2013; Hornberger, 2004). 
Multilingualism can be associated with biliteracy given the varying contexts and media in which languages are used. For instance, in a classroom setting students might have access to reading or writing systems in two (or more) languages for different purposes (Reyes, 2006). There is also a range of literacies (besides reading and writing) that reinforce students' cultural and home languages for communication in the classroom (Burcu et al., 2014). Hence, the multiliteracies approach advocated by Burcu et al., (2014) is a relevant one for the variety of sociocultural and linguistic resources that can facilitate students' access to knowledge, notably in the South African context.

In education, the concept of biliteracy as well as that of multilingualism entail the use of linguistic resources as capital with which to challenge English hegemony while affirming students' home languages, culture, and identity (Hopewell \& Escamilla, 2014). The growing number of linguistically diverse students across the world makes it more urgent that multilingualism and biliteracy be promoted. Both have been used as alternative strategies for ensuring that students thrive in multilingual environments (Giambo \& Szecsi, 2015).

In the South African context, many speakers of African languages are proficient in more than two languages other than English (Heugh, 2003; Prah, 2006) because there is mutual intelligibility between the African language groups such as the Nguni languages-isiXhosa, isiZulu, isiNdebele, and Siswati. However, the multilingual abilities of African language speakers are often measured against their proficiency in English only, and this compromises their rich linguistic repertoires which serve as, and potentially offer, social and academic resources (Prah, 2006).

Thus in multilingual South Africa, the concept of multiliteracy would be more appropriate than biliteracy given that some students have reading and writing literacies in more than two languages. However, given the focus and context of our research we still refer to biliteracy to investigate students' levels of literacy proficiency in accessing engineering texts in two languages (English and isiXhosa).

Hornberger's (2004) definition of biliteracy refers to forms of communication in two or more languages in and around writing. In our context, we therefore came to see the interrelationship between multilingualism and biliteracy because the students came from different language backgrounds yet they had to access electrical engineering content through the medium of English only.

It is against this backdrop that we provided students competent in English and isiXhosa with multilingual glossaries. Our purpose was to understand how isiXhosa-speaking students exploited linguistic resources by using their home language to make sense of electrical engineering concepts in English. Thus, our investigation is based on an alignment between our definitions of multilingualism, biliteracy, and epistemological access. We believe that these three concepts are interconnected and therefore relevant to the practices that should inform transformation and pedagogies in culturally and linguistically diverse contexts.

\section{Research Methodology}

Here follows a detailed explanation of the research methodology which includes sampling, research procedures, and ethical considerations observed in the procurement of data.

We created a qualitative research design in order to understand students' experience of using multilingual glossaries to gain access to knowledge in the field of electrical engineering. The appeal of qualitative research is that it takes place in the natural world. It is interactive, context-focused, humanistic, emergent, and basically interpretative (Marshall \& Rossman, 2011). Thus, our qualitative 
study was conducted in the Department of Engineering with first-year electrical engineering students in one higher education institution of the Western Cape.

\section{Sampling and Participants}

A convenience sample entails collecting information from participants who are easily accessible to the researcher (Etikan, Musa, \& Alkassim, 2016). Given that one of the authors worked directly with the students on a daily basis, it was easy and convenient to gain access to them. The engineering class from which the participants were drawn was multilingual and comprised students from different language groups such as English, Afrikaans, isiXhosa, and other South African languages. The majority were Afrikaans home-language speakers.

For the purpose of this study, we conveniently selected isiXhosa home-language speakers.

The option for engineering students was influenced by the fact that this field is regarded as one of the high-risk disciplines in an institution where students often need extra support. Also, as a science, engineering requires that students develop a conceptual understanding of technical procedures through problem solving. It uses specialised language or a register that is often dense and abstract (Jones, 2000). Students are expected to be creative and innovative as they transform ideas into useful products that bring about necessary and positive change in society. Thus the authors recognised the need for language support given that the performance analysis had indicated that language constituted one of the barriers to learning, particularly for black students who were mainly isiXhosa home-language speakers. Moreover, most had not studied engineering at school and they were struggling to understand certain concepts in this field.

The sample comprised 14 participants: eight female and six male students. All participants spoke isiXhosa as a home language, and their ages ranged from 19 to 22 years. They had matriculated at diverse schools. There were five students from township schools, three from rural schools, five from former white (Model C) schools and one from a private school. The majority of students (eight) came from under-resourced rural and township schools.

Students from the rural and township schools did isiXhosa as a home language and English as a second language or first additional language. They had been taught by isiXhosa home-language speakers. At school, the language of instruction was English (first additional language). In the former white and private schools, English was taught as a home language, and was also the language of instruction. Students from former white schools did isiXhosa at school as a third or second additional language so they had elementary reading and writing skills in isiXhosa. They were also fluent in speaking the language. The student from the private school did not study isiXhosa at school and had very limited reading and writing proficiency in it although she could speak the language.

Participants were selected on the basis that they were first-year students studying engineering and they had indicated that their home language was isiXhosa. They had shown interest in the project and a willingness to participate, and were thus available for interviews. Students were given pseudonyms for purposes of anonymity. Data were collected by means of open-ended questionnaires and focus group interviews as illustrated in the sections that follow.

\section{Questionnaires}

The questionnaires were open-ended and presented in English. The students were allowed to respond in either English or isiXhosa or they could mix languages, that is, shift between English and isiXhosa. 
The questionnaires were subdivided into themes that captured various elements relating to the aims of the study. For example, the first theme of the questionnaire covered students' biographical information including age, gender, first and additional languages studied at high school, as well as the location and type of school they attended (rural/township/private/former white schools). The second part was open-ended and dealt with the following issues:

- whether or not they used the glossaries, and what reason/s obtained

- frequency of glossary use

- benefits of glossary use

- challenges in using glossaries

- recommendations for development of multilingual glossaries.

The questionnaires were completed in one day and returned to the researcher. A preliminary analysis of the questionnaires was done before conducting focus group interviews with the same students. The aim was to identify gaps and areas that needed further probing in the interviewing session.

The next section describes how the focus group interviews proceeded.

\section{Focus Group Interviews}

As indicated, the focus group interviews were conducted with the same students who had completed the questionnaires. The purpose of the focus group interviews was to facilitate triangulation of, and elaboration on, certain issues. Triangulation was intended to increase the credibility and validity of the data obtained from the questionnaires by incorporating the differently-sourced viewpoints. It is helpful because it allows for cross-checking, confirmation, and completeness, which brings balance between two or more different types of research (Yeasmin \& Rahman, 2012).

Students were divided into two heterogenous groups with regard to gender and school background. Two focus groups were held, each lasting between 40 to 45 minutes. The first group consisted of eight students, and the second group comprised six. The number in each group was determined by students' availability. Students were divided into two groups in order to give individuals sufficient opportunity to express themselves freely. To accommodate all participants, the interviews were conducted in English and isiXhosa through code switching. A recording device was used once students had granted their permission. Student responses were then transcribed to facilitate data analysis.

\section{Ethical Considerations}

The research study adhered to ethics with regard to the participants' confidentiality, respect, and voluntary participation (de Vos, Strydom, Fouché, \& Delport, 2005; Henning, van Rensburg, \& Smit, 2004). Students' permission to participate in the study was sought well in advance, and comprehensive information about the aims and scope of the research was shared with all. We also ensured that their identity would be protected by using pseudonyms in reporting on the findings. Ethical clearance was obtained from the higher education institution at which one of the researchers is registered. 


\section{Data Analysis}

The findings of this study were established through an approach based on thematic analysis (Dainte \& Lightfoot, 2004) aimed at extracting conceptual significance from the data by examining and observing emerging patterns (Javadi \& Zarea, 2016).

On the basis of this approach, the themes that emerged from the data analysis pointed to the benefits and constraints of accessing knowledge through multilingual glossaries. Because student experience formed the nub of this enquiry, what follows is a discussion that hones in on students' multilingual and biliteracy development levels in the languages they were exposed to at high school and in higher education. We extend the discussion to incorporate the implications of multilingualism and biliteracy for transformation in higher education.

\section{Student Experiences}

The findings indicate that students' biliteracy abilities enriched their knowledge of engineering course content and also placed isiXhosa in a space where it was recognised as an intellectualised language. Unfortunately, the status quo (a monolingual English environment) obtained for students who lacked reading and writing skills in isiXhosa.

\section{Cognitive Benefits}

The analysed data revealed that students had different experiences with regard to the use of glossaries to support their learning. The benefits cited were in the cognitive domain and related to enrichment in the sphere of academic content knowledge. Students' responses seemed to be influenced by their high school backgrounds and the languages they had had more exposure to before they joined higher education. Some students indicated that the glossaries were useful for deepening their understanding of particular concepts in engineering. Both the questionnaire and focus group interview data showed that all the students $(n=8)$ who matriculated in townships and rural schools highlighted the benefits of glossaries. For instance, one of the female students (Nosipho) had this to say about the role of engineering glossaries in learning:

It gives us clear understanding of the things that are new to us in the field of engineering since the whole course is new to us.

This finding is unsurprising given that much has been documented about the value of the home language in facilitating students' epistemological access (Heugh, 2003; Mbekwa \& Nomlomo, 2013; Nomlomo, 2007; Prah, 2006; Webb, 2004). Recent research corroborates the cognitive benefits of the home language in various higher education disciplines such as language, academic literacy, and psychology (Mkhize et al., 2014; Ngcobo et al., 2016; Paxton \& Tyam, 2010). Similarly, the pedagogical value of glossaries is widely acknowledged by many scholars in the field of academic literacy (Beck, McKeown, \& Kucan 2008; Farstrup \& Samuels 2008; Graves, 2006; Hiebert \& Kamil 2005; Marzano, 2003). Additionally, research shows that there is a lot of code switching in township and rural schools where teachers themselves are not comfortable in teaching through the medium of English. As a result, learners leave school with low levels of proficiency for understanding academic texts in English.

The students' responses tied in with the frequency of the use of the glossaries. Because the township and rural students struggled with academic concepts, they referred to the glossaries whenever they experienced difficulties. However, the frequency of the use of these resources was influenced by the type of language used in translation. Three of the township students stated that although they made use of the glossaries as often as possible, on occasion they would struggle with the translations 
because some of the concepts are expressed in "pure" isiXhosa terms that they have not been exposed to in their daily communication. This was a case of language variation because there are standardised and nonstandardised varieties of isiXhosa (Nomlomo, 1993), which may block students' understanding of certain concepts (Nomlomo, 2014).

However, it appeared that students from former white and private schools did not benefit much from the multilingual glossaries. Only two of the five students who attended the former white school indicated that they "sometimes" referred to the glossaries for certain concepts.

This was an interesting finding because it highlighted the value of biliteracy: some students could move between languages to access knowledge in spite of having varying degrees of competence in the two languages (Hornberger, 2004). In the former case, students' literacy skills in English were stronger than their skills in isiXhosa and thus they were able to explore their literacies within both languages. In this way, they could gain epistemological access to relevant concepts and terminology in the field of engineering.

By contrast, it can be argued that students who were monolingual in English only were deprived of a source by which to enrich their knowledge. They were at a disadvantage with regard to accessing an additional resource to support or deepen their learning of concepts in engineering. This deficit may be assumed given that concepts are the building blocks of human knowledge, and they form an essential part of reasoning (O'Hara \& Prichard, 2009).

However, no students were assessed with the objective of verifying the extent to which they understood the concepts in their field.

\section{Linguistic Challenges}

The challenges that were experienced by students varied. Some had to do with the unfamiliar language or linguistic register and poor translation of terms from English into isiXhosa, while others were associated with impoverished vocabulary.

All the students $(n=5+1)$ who attended the former white schools and the private school experienced difficulties with isiXhosa terms that are not used in everyday communication. They struggled to understand some of these concepts, phrases, and expressions due to the nature of isiXhosa terms that were inaccessible. As a result, they did not find the isiXhosa section helpful although they showed a willingness to use it. In fact, some of them $(n=4)$ indicated that they no longer use the glossaries because they could not comprehend the isiXhosa part. This may have been due to the fact that they possessed more language and literacy competence in English because they had had limited exposure to isiXhosa language and literacy at primary and high school. In fact, one of them had not done isiXhosa at school, while others had done basic isiXhosa at a second additional language level, so their vocabulary was limited.

This illustrates the point that while effective vocabulary is needed to promote active, in-depth processing of words and concepts (Wood, 2001), the type of school students attend has an impact on how they perceive and interact with additional support. One of them responded thus:

Kukho amagama angaqondakaliyo enza isivakalisi singavakali sonke [There are words that do not make sense in a sentence]. 
Word or vocabulary learning is enhanced when students are actively involved in different vocabulary development activities rather than being treated as passive recipients of information (Bransford, Brown, \& Cocking, 1999).

One of the students indicated his willingness to use the glossaries, but the translated terminology appeared to be a barrier to the discourse of engineering. He acknowledged that the engineering discourse was scientific and characterised by abstract concepts (Jones, 2000) that may not have equivalents in isiXhosa:

English section is easier to understand because the terms are scientific and are not in everyday use on our Xhosa communities.

This finding supports Nomlomo's (2014) findings that translating scientific terms from English to isiXhosa may pose some challenges to meaning making. It does, however, depend on the approach one employs in the process (Jokweni, 2005; Nomlomo, 2014), that is, whether it is semasiological (description of terms) or onomasiological (use of equivalent words). In this instance, the latter approach was employed. From a sociocultural and linguistic point of view, these students could not tap into their linguistic capital because their home-language literacy skills were underdeveloped. In Hopewell and Escamilla's (2014) terms, the students' biliteracy trajectories were limited or impoverished. Consequently, the students could not capitalise on their home language as a resource as was the case with the students who were schooled in township and rural schools, and who were thus biliterate in English and isiXhosa. This may be read as the influence of English hegemony and the stigmatisation of African languages in South African education.

Moreover, the foregoing student's response reinforces the common myth that scientific terms can be accessed through English only (Prah, 2006). This view has also been challenged by a number of scholars who advocate for the intellectualisation of African languages (Kaschula \& Maseko, 2014; Nomlomo, 2014). Indeed, Kaschula and Maseko (2104) pointed out that language intervention should be at the level of the home, and the first additional languages, to support the intellectualisation of indigenous African languages.

This view resonates with the biliteracy pedagogies that assert that learning processes should capitalise on knowledge obtained through the introduction and exposure to literacy in more than one language rather than advocate being literate in the dominant language only (Giambo \& Szecsi, 2015; Hopewell \& Escamilla, 2014; Reyes, 2006).

\section{Students' Evaluation of the Glossaries}

The analysed data revealed that students had ideas about how to develop appropriate multilingual glossaries that would benefit the majority. So while they expressed appreciation for the glossaries, they also directed attention towards areas that needed to be improved. As noted earlier, for the majority, especially those who had been schooled in rural and township schools, the multilingual glossaries facilitated their understanding of concepts and this gave them hope for better performance in the course. 
They made suggestions for extending the glossary to include "difficult" terms, as indicated in the comment:

There should be some other terms added there in the multilingual glossary especially difficult terms.

The significance of this suggestion is that it has implications for the selection of terms, the basis of selection, and the agency in who participates in the selection process.

Some advocated the extension of the translation service to include modules and textbooks, adding that the whole electrical engineering course should be available in isiXhosa. While this suggestion sounds ambitious, it has implications for materials development in isiXhosa, which is indeed one of the ways of fostering its academic status (Prah, 2006).

According to Madiba (2010), the development of multilingual glossaries is an important intervention strategy for facilitating learning in different disciplines. New concepts can be coined to develop a new corpus for different content subjects in African languages, but subject specialists have to be involved. Students themselves can develop terms and registers in their own (African) languages (Paxton, 2009). A study by Mkhize et al., (2014) illustrated how such an initiative has been conducted with students at the University of KwaZulu-Natal.

\section{Implications for Transformation in Higher Education}

The findings of this study reveal the pivotal role played by language in enhancing and constraining epistemological access or meaningful learning (Ouane \& Glanz, 2010). They show that the student's home language is a useful resource in learning, irrespective of socioeconomic background. For example, while the rural and township students seemed to be disadvantaged in terms of socioeconomic status, they possessed a rich cultural and linguistic repertoire that was useful for accessing the multilingual glossaries. This distinguished them from their counterparts who were English monolinguals. Here was an indication that strong literacy skills in one's home language may be an advantage in accessing knowledge across different languages.

While we argue that multilingualism doesn't necessarily guarantee students' epistemological access to knowledge if their biliteracy skills are underdeveloped, it will be misleading to regard multilingualism as a problem rather than a resource in education. What this implies is that multilingual practices flourish where students have strong literacy skills in the languages targeted for teaching and learning. This indicates that there is an interrelationship between multilingualism and biiteracy (Hornberger, 2004), which entails not only the maintenance of the students' home languages, but also literacy development in two or more languages.

What it also suggests is that bilingual and biliterate students can capitalise on transferable skills, and that they have better metalinguistic and pragmatic awareness than monolingual students (Hopewell \& Escamilla, 2014; Reyes, 2006). The former have increased opportunities to access better learning.

So, the findings seem to corroborate the view that the goal of biliteracy is to affirm one's home language and cultural capital in knowledge construction (Burcu et al., 2014). This is how multilingualism and biliteracy methodologies contribute towards transforming language practices in the classroom. 
In addition, the findings suggest that societal and linguistic inequalities exert an influence on students' learning in higher education. The students from disadvantaged schools needed more language support than those from better resourced schools. However, the former had better opportunities to explore and construct knowledge in two languages. So, despite the challenges that students mentioned with regard to the multilingual glossaries, it is apparent that they benefited from these by having gained a better understanding of terms germane to electrical engineering. However, this did vary according to students' biliteracy trajectories.

What this suggests is that higher education institutions have to respond not only to the increasing cultural and linguistic diversity of the student population, but also to the linguistic inequalities it brings. This implies revisiting approaches to teaching and learning and curricula; it necessitates employing transformative pedagogies to produce active citizens, critical thinkers, and prospective workers who are able to function in a connected world (Heleta, 2016). For example, the multilingual pedagogical approach, proposed by Haukåsa (2015), is grounded in the value and benefits of the home language in the acquisition of additional languages, while it also recognises the social and cognitive aspects of learning. It is related to the biliteracy pedagogy that also capitalises on knowledge constructed through the use of two or more languages (Hopewell \& Escamilla, 2014). Both advocate equality, freedom, and justice, which are cornerstones of democracy (Nagda et al., 2003).

With the recent student protests in many South African higher education institutions, the discourse on the "decolonisation" and "Africanisation" of the curriculum as expressive of social justice has gained momentum (Bulfin, 2009). At the centre of this discourse, is the question of which language/s are to be used in teaching and learning in higher education.

For Afrikaans-speaking students (for example, at the universities of the Free State, Pretoria, and Stellenbosch), the use of English as the main medium of instruction is regarded as a compromise because it prevents them from accessing knowledge through their home languages. Yet this critique is not the case for black students who do not have the privilege of learning through the medium of their home languages at all (Desai, 2016).

So, as part of the transformation or the decolonising agenda, teaching methods should capitalise on the sociocultural significance of learning. Higher education institutions have a responsibility to provide support for multilingual practices. In particular, they should focus on students' reading and writing biliteracy, which should include African languages for all the students. There should also be a focus on academic staff training because many academics are not competent in African languages. Thus engaging in transformative multilingual and biliteracy pedagogies will be a futile exercise if the language transformation agenda does not also involve academics.

Finally, higher education institutions should examine their language policies to integrate the marginalised African languages and cultures into the higher education system. This entails developing African languages for academic use and providing appropriate teaching and learning materials (UNESCO, 2010), especially in the sciences. Kaschula and Maseko (2014) thus emphasised the need for corpus and status planning to enhance the intellectualisation of African languages. On the trajectory of the same argument is Prah's (2006) suggestion of an African-centred approach to development because it will allow the majority of South Africans to be involved in education through their diverse cultures and languages. This could lead to advancement in the economy and development of the country. 
To enhance the use of two or more languages in teaching and learning, more research is needed on transformative pedagogies - such as multilingual and biliteracy pedagogies-particularly in initiatives that seek to develop the marginalised indigenous African languages as intellectualised languages. There is a need to explore language transformation strategies that embrace language diversity in South African higher education. African languages have to be empowered as languages of science and technology (Prah, 2006) through adequate translation materials development. Institutions of higher education should provide enabling learning opportunities and transformative pedagogies that embrace equity, freedom, and social justice to enhance students' equal epistemological access to knowledge through multilingualism and biliteracy.

\section{Conclusion}

While the findings of this study seem familiar with regard to students' experiences of multilingual glossaries, they raise an interesting matter concerning the need for investing in students' reading and writing. Biliteracy is a means of maintaining and valuing students' home languages in higher education, especially in African languages. The findings are useful because they provide insight into the current linguistic practices in some higher education institutions-into how language and literacy development can either facilitate or hinder students' access to knowledge. They indicate that multilingual materials such as glossaries do not automatically guarantee epistemological access if they are not in sync with the students' multilingual and biliteracy trajectories. Multilingualism is a necessary transformative approach, but students' (bi)literacy development in African languages should also be prioritised and strengthened to facilitate better learning and teaching practices for all.

\section{References}

Alexander, N. (2005). Towards mother tongue-based bilingual education: Summary of input given at a workshop hosted by the Eastern Cape Department of Education. Multilingualism Action Group Newsletter, 2, 9.

Alidou, H. (2004). Medium of instruction in post colonial Africa. In J. W. Tollefson \& A. B. Tsui (Eds.), Medium of instruction policies: Which agenda? Whose agenda? (pp. 195-215). Mahwah, USA: Lawrence Erlbaum.

Alidou, O., \& Mazrui, A. M. (1999). The language of Africa-centred knowledge in South Africa. In M. Palmberg (Ed.), National identity and democracy in Africa (pp. 101-118). Uppsala, Sweden: Nordic Africa Institute.

Antia, B. E., \& Dyers, C. (2016). Epistemological access through materials in multiple modes and language varieties: The role of ideologies and multilingual literacy practices in student evaluations of such materials at a South African university. Language Policy, 5(4), 525-545.

Bamgbose, A. (2005). Mother tongue education: Lessons learnt from the Yoruba experience. In B. Brock-Utne \& R. K. Hopson (Eds.), Languages of instruction for emancipation: Focus on postcolonial contexts and considerations (pp. 231-255). Dar es Salaam, Tanzania: Mkuki na Nyota.

Banda, F. (2006). Investigating the role of study groups and mediated academic literacy events at the University of the Western Cape. In B. Brock-Utne, Z. Desai, \& M. Qorro (Eds.), Focus on fresh data on the Language of Instruction Debate in Tanzania and South Africa (pp. 232-251). Cape Town, South Africa: African Minds.

Beck, I. L. McKeown, M. G., \& Kucan, L. (2008). Creating robust vocabulary: Frequently asked questions and extended examples. New York, USA: Guilford.

Bransford, J., Brown, A., \& Cocking, R. (1999). How people learn: Brain, mind, experience and school. Washington, USA: National Research Council. 
Brock-Utne, B. (2005). "But English is the language of science and technology." On the language of instruction in Tanzania. In B. Brock-Utne, Z. Desai, \& M. Qorro (Eds.), LOITASA Research in Progress (pp. 160-188). Dar-es-Salaam, Tanzania: KAD Associates.

Bulfin, M. P. (2009). Perspectives on higher education in Africa: Fieldnotes on trends, themes, challenges and opportunities. Ufahamu: A Journal of African Studies, (36)1, 1-9.

Burcu, Y. M., Fannin, J., Montanero, M., \& Cummins, J. (2014). A multilingual and multimodal approach to literacy teaching and learning in urban education: A collaborative inquiry in an inner city elementary school. Frontiers in Psychology, 5, 533.

Chumbow, B. S. (1990). The place of the mother tongue in the national policy on education. In E. N. Emenanjo (Ed.), Multilingualism, minority languages and language policy in Nigeria (pp. 61-72). Agbor, Nigeria: Central Books Limited.

Chumbow, B. S. (2013). Mother tongue-based multilingual education: Empirical foundations, implementation strategies and recommendations for new nations. In H. Mcllwraith (Ed.), Multilingual education in Africa: Lessons from the Juba Language-in-Education Conference (pp. 2437). London, UK: British Council.

Constitution of the Republic of South Africa Act, No. 108 of 1996.

Dainte, C., \& Lightfoot, C. (Eds.). (2004). Narrative analysis. Studying the development of individuals in society. Thousand Oaks, USA: SAGE.

De Vos, A. S., Strydom, H., Fouché, C. B., \& Delport, C. S. L. (2005). Research at grass roots for the social sciences and human service professions (3rd ed.). Pretoria, South Africa: van Schaik.

Department of Education (DoE). (1997). Language in education policy. Government Gazette, 17997 (383) Pretoria, South Africa: DoE.

Department of Education (DoE). (2002) Language policy for higher education. Pretoria, South Africa: DoE.

Desai, Z. (2003). A case for mother tongue education? In B. Brock-Utne, Z. Desai, \& M. Qorro (Eds.), Language of instruction in Tanzania and South Africa (pp. 45-68). Dar-es-Salaam, Tanzania: E\&D.

Desai, Z. (2016). Learning through the medium of English in multilingual South Africa: Enabling or disabling learners from low income contexts? Comparative Education, 52(3), 343-358.

Etikan, I., Musa, S. A., \& Alkassim, R. S. (2016). Comparison of convenience sampling and purposive sampling. American Journal of Theoretical and Applied Statistics, 5(1), 35-38.

Farstrup, E., \& Samuels, S. J. (2008). Vocabulary instruction: A critical component for skilful reading. What research has to say about vocabulary instruction. Newark, USA: International Reading Association.

Fisher, G., \& Scott, I. (2011). The role of higher education in closing the skills gap in South Africa. Background Paper 3 for "Closing the skills and technology gap in South Africa." Washington, USA: World Bank.

Giambo, D., \& Szecsi, T. (2015). Promoting and maintaining bilingualism and biliteracy: Cognitive and biliteracy benefits and strategies for monolingual teachers. The Open Communication Journal, 9(1), 56-60.

Graves, M. F. (2006). Teaching individual words: One size does not fit all. Newark, USA: International Reading Association.

Haukåsa, A. (2015). Teachers' beliefs about multilingualism and a multilingual pedagogical approach. International Journal of Multilingualism. http://doi:10.1080/14790718.2015.1041960 
Heleta, S. 2016. Decolonisation of higher education: Dismantling epistemic violence and Eurocentrism in South Africa. Transformation in Higher Education, 1(1). http://doi.org/10.4102/thev1i1.9

Henning, E., van Rensburg, W., \& Smit, B. (2004). Finding your way in qualitative research. Pretoria, South Africa: van Schaik.

Heugh, K. (2003). Language policy and democracy in South Africa: The prospects of equality within rights-based policy and planning (Doctoral dissertation). University of Stockholm, Sweden.

Hibbert, L. 2011. Language development in higher education: Suggested paradigms and their applications in South Africa. Southern African Linguistics and Applied Studies, 29(1), 31-42.

Hiebert, E. H., \& Kamil, M. L. (2005). Teaching and learning vocabulary: Bringing research to practice. Mahwah, USA: Laurence Erlbaum.

Hopewell, S., \& Escamilla, K. (2014). Development in immersion contexts. Journal of Immersion and Content-based Language Education, 2(2), 181-195.

Hornberger, N. H. (2004). The continua of biliteracy and the bilingual educator: Educational linguistics in practice. Bilingual Education and Bilingualism, 7(2-3), 155-171.

Jansen, J. (2008). Reflections on meaningful access to education. South African Child Gauge, 2008/2009, 7-8.

Javadi, M., \& Zarea, K. (2016). Understanding thematic analysis and its pitfalls. An International Nursing Journal, 1(1), 33-39.

Jokweni, M. (2004). Problems associated with the creation of isiXhosa terms for special subjects: The case of geography and science. In B. Brock-Utne, Z. Desai, \& M. Qorro (Eds.), Researching the language of instruction in Tanzania and South Africa (pp. 169-176). Cape Town, South Africa: African Minds.

Jones, C. (2000). The role of language in the learning and teaching of science. In M. Monk \& J. Osborne (Eds.), Good practice in science teaching (pp. 88-103). Philadelphia, USA: Open University Press.

Kaschula, R. H., \& Maseko, P. (2014). The Intellectualisation of African languages, multilingualism and education: A research-based approach: Alternation Special Edition, 13, 8-35.

Madiba, M. (2010). Fast-tracking concept learning to English as an additional language (EAL) students through corpus-based multilingual glossaries. Alternation, 17(1), 225-248.

Marshall, C., \& Rossman, G. B. (2011). Primary collection methods designing qualitative research. Los Angeles, USA: SAGE.

Marzano, R. J. (2003). Direct vocabulary instruction: An idea whose time has come. In B. Williams (Ed.), Closing the achievement gap: A vision for challenging beliefs and practices (pp. 48-66). Alexandria, USA: Association for Supervision and Curriculum Development.

Mbekwa, M., \& Nomlomo, V. (2013). Voices from the classroom: Teacher and learner perceptions on the use of the learners' home language in the teaching and learning of school mathematics and science. In D. B. Napier \& S. Majhonovich (Eds.), Education, dominance and identity (pp. 133-149). Rotterdam, Netherlands: Sense.

Mkhize, N., Dumisa, N., \& Chitindingu, E. (2014). Democratising access and success: IsiZulu terminology and development and bilingualism instruction in psychology at the University of KwaZulu-Natal. Alternation Special Edition, 13, 128-154.

Moeketsi, L., \& Maile, S. (2008). High university drop-out rates: A threat to South Africa's future. Pretoria, South Africa: Human Sciences Research Council.

Molosiwa, A. (2005). Extinction or distinction? Empowering seTswana as the medium of instruction and instrument in Botswana schools. In B. Brock-Utne \& R. K. Hopson (Eds.), Languages of 
instruction for emancipation: Focus on postcolonial contexts and considerations (pp. 175-198). Dar es Salaam, Tanzania: Mkuki na Nyota.

Morrow, W. E. (1994). Entitlement and achievement in education. Studies in Philosophy and Education, 13, 33-47.

Motala, S., Dieltiens, V., \& Sayed, Y. (2009). Physical access to schooling in South Africa: Mapping dropout, repetition and age-grade progression in two districts. Comparative Education, 45(2), 251263.

Nagda, B. N., Gurin, P., \& Lopez, G. (2003). Transformative pedagogy for democracy and social justice. Race Ethnicity and Education, 6(2), 165-191.

Ngcobo, S., Ndaba, N., Nyangiwe, B., Mpungose, N. C., \& Jamal, R. (2016). Translanguaging as an approach to address language inequality in South African higher education: Summary writing skills development. Critical Studies in Teaching and Learning, 4(2), 10-27.

Nomlomo, V. (1993). Language variation in the Xhosa speech community and its impact on children's education (Unpublished master's thesis). University of Cape Town, South Africa.

Nomlomo, V. (2007). Science teaching and learning through the medium of English and isiXhosa: A comparative study at two primary schools in the Western Cape (Unpublished doctoral dissertation). University of the Western Cape, South Africa.

Nomlomo, V. (2014). Reflections on the use of an African language in science teaching and learning in the intermediate phase: A case study in two Western Cape primary schools. Alternation Special Edition, 13, 209-235.

Nomlomo, V., \& Vuzo, M. (2014). Language transition and access to education: Experiences from Tanzania and South Africa. International Journal of Educational Studies, 1(2), 73-82.

O'Hara, S., \& Prichard, R. H. (2009) Teaching vocabulary with hypermedia, 6-12. Colombus, USA: Prentice Hall.

Ouane, A., \& Glanz, C. (Eds.). (2010) Optimising learning, education and publishing in Africa: The language factor. Harmburg, Germany: UNESCO Institute for Lifelong Learning and the Association for the Development of Education in Africa.

Paxton, M. I. J. (2009). "It's easy to learn when you are using your home language but with English you need to start learning language before you get to the concept": Bilingual concept development in an English-medium university in South Africa. Journal of Multilingual and Multicultural Development, 30(4), 345-359.

Paxton, M., \& Tyam, N. (2010). Xhosalising English? Negotiating meaning and identity in business economics. Southern Linguistics and Applied Language Studies, 28(3), 247-257.

Plüddemann, P., Nomlomo, V., \& Jabe, N. (2010). Using African languages for teacher education. Alternation, 17(1), 72-91.

Prah, K. K. (2006). Challenges to the promotion of indigenous languages in South Africa. Review commissioned by the Foundation for Human Rights in South Africa. Cape Town, South Africa: Centre for Advanced Studies of African Society.

Reyes, I. (2006). Exploring connections between emergent biliteracy and bilingualism. Journal of Early Childhood Literacy, 6(3), 267-292.

Strydom, J. F., \& Mentz, M. (2010). Focusing the student experience on success through engagement. Pretoria, South Africa: Council on Higher Education.

UNESCO. (2006). Promoting literacy in multilingual settings. Bangkok, China: UNESCO. 
(UNESCO). (2010). Why and how Africa should invest in African languages and multilingual education: An evidence and practice-based policy advocacy brief (pp. 1-66). Harmburg, Germany: Institute for Lifelong Learning.

Van der Walt, C. (2013). Multilingual higher education: Beyond English-medium orientations. Bristol, UK: Multilingual Matters.

Webb, V. (2004). Language policy in post-apartheid South Africa. In J. W. Tollefson \& A. B. M. Tsui (Eds.), Medium of instruction policies: Which agenda? Whose agenda? (pp. 217-240). Mahwah, USA: Lawrence Erlbaum.

Wood, J. (2001). Can software support children's vocabulary development? Language learning and technology, 5(1), 166-201.

Yeasmin, S., \& Rahman, K. F. (2012). Triangulation research method as the tool of social science research. BUP Journal, 1(1), 154-163. 